\title{
2011s-61
}

\section{Set Coverage and Robust Policy}

\author{
Marc Henry, Alexei Onatski
}

Série Scientifique
Scientific Series

\section{Montréal}

Octobre 2011

(C) 2011 Marc Henry, Alexei Onatski. Tous droits réservés. All rights reserved. Reproduction partielle permise avec citation du document source, incluant la notice ().

Short sections may be quoted without explicit permission, if full credit, including @ notice, is given to the source.
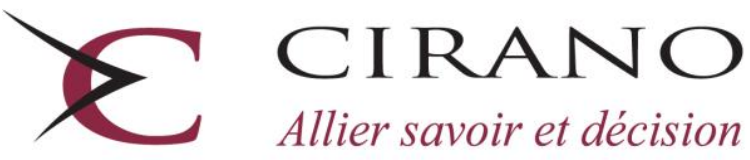

Allier savoir et décision

Centre interuniversitaire de recherche en analyse des organisations 


\section{CIRANO}

Le CIRANO est un organisme sans but lucratif constitué en vertu de la Loi des compagnies du Québec. Le financement de son infrastructure et de ses activités de recherche provient des cotisations de ses organisations-membres, d'une subvention d'infrastructure du Ministère du Développement économique et régional et de la Recherche, de même que des subventions et mandats obtenus par ses équipes de recherche.

CIRANO is a private non-profit organization incorporated under the Québec Companies Act. Its infrastructure and research activities are funded through fees paid by member organizations, an infrastructure grant from the Ministère du Développement économique et régional et de la Recherche, and grants and research mandates obtained by its research teams.

\section{Les partenaires du CIRANO}

\section{Partenaire majeur}

Ministère du Développement économique, de l'Innovation et de l'Exportation

\section{Partenaires corporatifs}

Autorité des marchés financiers

Banque de développement du Canada

Banque du Canada

Banque Laurentienne du Canada

Banque Nationale du Canada

Banque Royale du Canada

Banque Scotia

Bell Canada

BMO Groupe financier

Caisse de dépôt et placement du Québec

\section{CSST}

Fédération des caisses Desjardins du Québec

Financière Sun Life, Québec

Gaz Métro

Hydro-Québec

Industrie Canada

Investissements PSP

Ministère des Finances du Québec

Power Corporation du Canada

Rio Tinto Alcan

State Street Global Advisors

Transat A.T.

Ville de Montréal

\section{Partenaires universitaires}

École Polytechnique de Montréal

HEC Montréal

McGill University

Université Concordia

Université de Montréal

Université de Sherbrooke

Université du Québec

Université du Québec à Montréal

Université Laval

Le CIRANO collabore avec de nombreux centres et chaires de recherche universitaires dont on peut consulter la liste sur son site web.

Les cahiers de la série scientifique (CS) visent à rendre accessibles des résultats de recherche effectuée au CIRANO afin de susciter échanges et commentaires. Ces cahiers sont écrits dans le style des publications scientifiques. Les idées et les opinions émises sont sous l'unique responsabilité des auteurs et ne représentent pas nécessairement les positions du CIRANO ou de ses partenaires.

This paper presents research carried out at CIRANO and aims at encouraging discussion and comment. The observations and viewpoints expressed are the sole responsibility of the authors. They do not necessarily represent positions of CIRANO or its partners. 


\title{
Set Coverage and Robust Policy *
}

\author{
Marc Henry ${ }^{\dagger}$, Alexei Onatski $i^{*}$
}

\section{Résumé / Abstract}

We show that confidence regions covering the identified set may be preferable to confidence regions covering each of its points in robust control applications.

Mots clés : partial identification, set coverage, maxmin expected utility, robust control.

Codes JEL : C44

\footnotetext{
* Financial support from SSHRC Grant 410-2010-242 is gratefully acknowledged. Publised in Economics Letters.

${ }^{\dagger}$ Departement de sciences économiques, Université de Montréal, C.P. 6128, succursale Centre-ville, Montréal, Québec, H3C 3J7, Canada. marc.henry@umontreal.ca.

Faculty of Economics, Cambridge University, Austin Robinson Building, Sidgwick Avenue, Cambridge CB3 9DD, UK, ao319@cam.ac.uk.
} 
MARC HENRY (UNIVERSITY OF MONTREAL) ALEXEI ONATSKI (UNIVERSITY OF CAMBRIDGE)

When conducting inference on partially identified parameters, Imbens and Manski (2004) pointed out that confidence regions may cover the whole identified set with a prescribed probability, to which we shall refer as set coverage, or they may cover each of its points with a prescribed probability, to which we shall refer as point coverage. Since set coverage implies point coverage, confidence regions satisfying point coverage are generally preferred on the grounds that they may be more informative. The object of this note is to describe a decision problem in which, contrary to received wisdom, point coverage is clearly undesirable.

Consider a random vector $s=(X, \varepsilon)$ on $\{1, \ldots, N\}$. Call realizations $s_{i}, i=1, \ldots, N$, of this random vector states of the world, and call their collection $S=\left\{s_{1}, \ldots, s_{N}\right\}$. Suppose states of the world are partially observable, by which we mean that the realizations $\left\{x_{1}, \ldots, x_{N}\right\}$ of $X$ can be observed over repeated experiments, but not the realizations $\left\{\varepsilon_{1}, \ldots, \varepsilon_{N}\right\}$ of $\varepsilon$. Call $P_{X}$ the probability mass function of random vector $X$. Let $\Theta$ be a set of models for the states, defined by the fact that for each $\theta \in \Theta, P_{\theta}$ denotes a probability mass function for the random vector $(X, \varepsilon)$. The identified set $\Theta_{I}$ is defined in the following way:

$$
\Theta_{I}=\left\{\theta \in \Theta: \sum_{j=1}^{N} P_{\theta}\left(x_{i}, \varepsilon_{j}\right)=P_{X}\left(x_{i}\right) \text { for } i=1, \ldots, N\right\} .
$$

More generally, any additional a priori restriction on the joint distribution of $(X, \varepsilon)$ can be incorporated in the definition of the identified set.

Suppose a decision maker may choose among actions in a set $\mathcal{A}=\left\{a_{1}, \ldots, a_{K}\right\}$. The actions may be treatments, as in Manski (2004), or policy controls as in Brainard (1967). Actions in $\mathcal{A}$ are defined as functions from $S$ to real valued outcomes. Call $U(a, \theta)$ the ex-ante utility of the decision maker, when she knows $P_{\theta}$ to be the true data generating process for $(X, \varepsilon)$. Typically, this will be von Neumann-Morgenstern expected utility $U(a, \theta)=\int a(s) d P_{\theta}(s)$. We shall consider two robust decision making procedures based on the identified set: (i) maxmin, where the decision maker maximizes the functional evaluation $V(a)=\min _{\Theta_{I}} U(a, \theta)$ over $\mathcal{A}$ and (ii) minmax regret, where the decision maker maximizes $V(a)=\min _{\Theta_{I}}\left[U(a, \theta)-\max _{a \in \mathcal{A}} U(a, \theta)\right]$ over $\mathcal{A}$. The arguments we make do not depend on which of the two options (i) or (ii) is chosen, so we shall concentrate on a maxmin decision maker.

The decision maker is supposed to have access to two types of confidence regions for $\Theta_{I}$ based on repeated sampling in the state space. A region covering the identified set called $\Theta_{S C}$ such that $\mathbb{P}\left(\Theta_{I} \in \Theta_{S C}\right)=1-\alpha$ and a region covering each point of the identified set called $\Theta_{P C}$ such that $\min _{\theta \in \Theta_{I}} \mathbb{P}\left(\theta \in \Theta_{P C}\right)=1-\alpha$. Without necessarily subscribing to the learning model of Epstein and 
Schneider (2007), we appeal to Anderson, Hansen, and Sargent (2003) and "assume that our decision maker worries about alternative models that available data cannot readily dispose of". Hence, the decision maker considers two decision rules based on the two respective confidence regions. The decision rule based on $\Theta_{S C}$ consists in choosing $\hat{a}_{S C}$ in $\mathcal{A}$ to maximize $\min _{\theta \in \Theta_{S C}} U(a, \theta)$ and the decision rule based on $\Theta_{P C}$ consists in choosing $\hat{a}_{P C}$ in $\mathcal{A}$ that maximizes $\min _{\theta \in \Theta_{P C}} U(a, \theta)$. The decision rule based on $\Theta_{S C}$ is robust in the sense that

$$
\mathbb{P}\left(\min _{\theta \in \Theta_{I}} U\left(\hat{a}_{S C}, \theta\right) \geq \min _{\theta \in \Theta_{S C}} U\left(\hat{a}_{S C}, \theta\right)\right) \geq 1-\alpha,
$$

so that $\min _{\theta \in \Theta_{S C}} U(a, \theta)$ provides a lower bound for the actual utility functional $V\left(\hat{a}_{S C}\right)$ with probability at least as large as $1-\alpha$. The decision rule based on $\Theta_{P C}$, however, is not robust as will be shown with the following example that we contrived in the simplest possible way for expositional purposes.

Let $\{1, \ldots, N\}$ be a population of individuals and let $X \in\{F, M\}$ be their gender and $\varepsilon \in\{T, N T\}$ be their talent ( $T$ for talented and $N T$ for not so talented). Half the population is male and half the population is talented, but the correlation $\theta$ between talent and gender is unknown. The decision maker is a social planner who can offer an education opportunity to women only (action $a_{1}$ ), to men only (action $a_{2}$ ) or to everyone (action $a_{3}$ ). The net benefit of offering the education opportunity to a talented person is $B$. The net benefit of offering the education opportunity to a not so talented person is $-B$ (wasted resources). The net benefit of failing to offer the education opportunity to a not so talented person is zero. Finally, the net benefit of failing to offer the education opportunity to a talented person is $-B$ (wasted talent). Assume that the parameter set is equal to $\Theta=\left\{\theta_{1}, \theta_{2}, \theta_{3}, \theta_{4}\right\}$, where under $\theta_{1}$ all talent is male, and under $\theta_{2}$ all talent is female, under $\theta_{3}$ everyone is talented and under $\theta_{4}$ no one is talented. Given the a priori constraints on the joint distribution of gender and talent, the identified set is $\Theta_{I}=\left\{\theta_{1}, \theta_{2}\right\}$. Now, with von Neumann-Morgenstern expected utility, we have:

$$
U\left(a, \theta_{1}\right)=\frac{1}{2} U(a(F, N T))+\frac{1}{2} U(a(M, T))=\left\{\begin{array}{rll}
-B & \text { if } & a=a_{1} \\
B / 2 & \text { if } & a=a_{2} \\
0 & \text { if } & a=a_{3}
\end{array}\right.
$$

and

$$
U\left(a, \theta_{2}\right)=\frac{1}{2} U(a(F, T))+\frac{1}{2} U(a(M, N T))=\left\{\begin{array}{rll}
B / 2 & \text { if } & a=a_{1} \\
-B & \text { if } & a=a_{2} \\
0 & \text { if } & a=a_{3}
\end{array}\right.
$$


MARC HENRY (UNIVERSITY OF MONTREAL) ALEXEI ONATSKI (UNIVERSITY OF CAMBRIDGE)

Note that $\mathbb{P}\left(\theta_{1} \notin \Theta_{S C}\right.$ or $\left.\theta_{2} \notin \Theta_{S C}\right)=\alpha$, whereas for $\Theta_{P C}$ we only require that either $\mathbb{P}\left(\theta_{1} \notin\right.$ $\left.\Theta_{P C}\right) \leq \alpha$ and $\mathbb{P}\left(\theta_{2} \notin \Theta_{P C}\right)=\alpha$, or $\mathbb{P}\left(\theta_{1} \notin \Theta_{P C}\right)=\alpha$ and $\mathbb{P}\left(\theta_{2} \notin \Theta_{P C}\right) \leq \alpha$. If $\Theta_{P C}$ is more informative than $\Theta_{S C}$, then $2 \alpha \geq \mathbb{P}\left(\theta_{1} \notin \Theta_{P C}\right.$ or $\left.\theta_{2} \notin \Theta_{P C}\right)>\alpha$. Take the case $\theta_{1} \notin \Theta_{P C}$ and suppose for clarity that $\Theta_{P C}=\left\{\theta_{2}\right\}$, then $\min _{\theta \in \Theta_{P C}} U(a, \theta)=B / 2$ if $a=a_{1},-B$ if $a=a_{2}$ and 0 if $a=a_{3}$; and symmetrically if $\theta_{2} \notin \Theta_{P C}$. Hence, when $\theta_{j} \notin \Theta_{P C}$, the action that maximizes $\min _{\theta \in \Theta_{P C}} U(a, \theta)$ is $\hat{a}_{P C}=a_{j}$ and $\min _{\theta \in \Theta_{I}} U\left(\hat{a}_{P C}, \theta\right)=\min _{\theta \in \Theta_{I}} U\left(a_{j}, \theta\right)=-B$ which can be much smaller than $\min _{\Theta_{P C}} U\left(a_{j}, \theta\right)=B / 2$. Hence the action taken on the basis of the region with point coverage yields a utility that may be much smaller than it appears with a probability strictly larger than $\alpha$. In contrast $\hat{a}_{S C}=a_{3}$ with probability at least $1-\alpha$ so $\min _{\Theta_{S C}} U\left(\hat{a}_{S C}, \theta\right)=0$ and

$\min _{\Theta_{I}} U\left(\hat{a}_{S C}, \theta\right)=0$ with probability at least $1-\alpha$, so that decision based on the region providing set coverage does not suffer from the same lack of robustness.

\section{REFERENCES}

Anderson, E., L. Hansen, and T. Sargent (2003): "A quartet of semigroups for model specification, robustness, prices of risk, and model detection," Journal of the European Economic Associaltion, pp. 68-123.

Brainard, W. (1967): "Uncertainty and the Effectiveness of Policy," American Economic Review, pp. $411-425$.

Epstein, L., and M. Schneider (2007): "Learning under ambiguity," Review of Economic Studies, 74, 1275-1303.

Imbens, G., and C. Manski (2004): "Confidence intervals for partially identified parameters," Econometrica, 72, 1845-1859.

MAnski, C. (2004): "Statistical treatment rules for heterogeneous populations," Econometrica, pp. 1221-1246. 